
\title{
25 Research Square \\ Orthorexia Nervosa Risk and associated factors among Chilean nutrition students: A pilot study.
}

\section{Manuel Villa}

Universidad Mayor, Temuco

\section{Nicole Opawsky}

Universidad Mayor, Temuco

\section{Sara Manriquez}

Universidad Mayor, Temuco

Nicole Ananías

Universidad Mayor, Temuco

Pablo Vergara-Barra

Universidad de Concepcion

Marcell Leonario ( $\nabla$ marcell.leonario@gmail.com )

Universidad Mayor, Temuco https://orcid.org/0000-0001-5807-9709

\section{Research Article}

Keywords: orthorexia nervosa, nutrition students, Chilean university students

Posted Date: August 14th, 2021

DOl: https://doi.org/10.21203/rs.3.rs-797425/v1

License: (1) This work is licensed under a Creative Commons Attribution 4.0 International License. Read Full License

Version of Record: A version of this preprint was published at Journal of Eating Disorders on January 11th, 2022. See the published version at https://doi.org/10.1186/s40337-022-00529-6. 


\section{Abstract}

Background: Orthorexia nervosa (ON) is characterized by an excessive, obsessive concern with healthy eating generating psychological complications and even malnutrition at a caloric and proteinic level. Current evidence suggests that people with greater food knowledge are the most likely to be affected, placing nutrition students as a populational risk group. Since there are no nationwide studies dealing with orthorexia nervosa in this risk group, the present pilot study intends to identify risk factors for orthorexia nervosa in a sample of Nutrition and Dietetics students in Chile.

Method: a descriptive cross-sectional pilot study was done on 90 Nutrition and Dietetics students at a specific school, representing $70 \%$ of its population. The ORTHO-11-ES instrument was applied to determine ON risk, along with consulting about attitudinal, physical-clinical and social variables. Association was determined in GraphPad PRISM 8.0®. This study was approved by the university Ethics Committee based on the Helsinki Declaration.

Results: $23.3 \%$ of the studied population was at risk of suffering ON. Associated variables were being in the second year of their major (OR 2.22), coming from a charter school (OR 3.00) and cohabitation being limited to $\leq 1$ person (OR 2.47). Curiously, declared physical activity limits are associated to the risk of suffering ON (Sedentary OR 2.42, Heavy OR 3.53), as well as time spent on the social network Instagram ( $<1$ hour OR $2.77,>3$ hours OR 1.80).

Conclusions: There is an ON risk prevalence of $23.3 \%$ in the present pilot sample under study, indicating that years of study, cohabitation, secondary educational establishment, physical activity and Instagram use constitute associated factors for the studied condition. Some results vary from international evidence, describing a dual nature in the variables for Instagram time and declared physical activity for $\mathrm{ON}$ risk. This study needs replication in more representative samples and longitudinal character with control groups which can confirm the studied elements as $\mathrm{ON}$ risk factors.

\section{Introduction}

Orthorexia nervosa (ON), first described by Steven Bratman in 1997, is defined as an eating disorder characterized by excessive, obsessive worry about healthy eating (1). Among its diagnostic criteria are a strong anxiety about affirmative and restrictive dietary practices to aspire to optimal health, accompanied by exaggerated fear over the appearance of diseases and shame about personal physical condition (2). This mental condition becomes complicated when dietary practices include total restriction of culinary ingredients or even entire food groups, along with fasting, which over time can become increasingly prolonged. It affects food choice, planning, acquisition, preparation and consumption (Table 1), generating both psychological and physical complications, associated with malnutrition at the calorie, protein and macronutrient levels and causing irreversible health damage, as occurs with other eating disorders including Bulimia and Anorexia Nervosa $(3,4)$.

Worldwide, descriptive studies over the last decade have reported a prevalence in the general population of $6.9 \%-90 \%$ (5); however, recent publications have reported that the numbers are limited to $1-3 \%$ (6), with the preceding figures corresponding to risk, and not diagnosis in itself. Studies in Chile which have attempted to measure this condition are in early stages and limited to specific age groups. The only report from Jerez et al., is on risk evaluation for $\mathrm{ON}$ in secondary students (7), reporting at $30.7 \%$ in a sample of 205 adolescents, 
supporting the premise that this age group is an at-risk population. Similarly, this category also includes health care professionals (58\% at risk) (8) and above all, people with greater knowledge about food and nutrition. Studies in Latin America and Western Europe report an ON risk prevalence among Nutrition and Dietetics students of around 70\% (9), placing them as the most affected at-risk group, as also occurs with sports science professionals (10).

The previously described points contextualize a worrying situation in Chile, due to the rising numbers of Nutrition students between 2007 and 2015 (65.5\%), only exceeded by two other health care majors. 16,000 students are projected for the present year, increasing the size of the at-risk group $(11,12)$.

Considering how the condition in question can gravely impact the health of its sufferers, and that there are currently no national-level ON studies in this at-risk group, the present pilot study intends to identify the associated risk factors for $\mathrm{ON}$ in Nutrition students. We will first apply the ORTHO-11-ES instrument to determine ON risk prevalence, and then characterize sociodemographic, educational and attitudinal aspects. Based on the evaluated variables, we will determine their associations and the ORTHO-11-ES results, in order to establish an important precedent for identifying possible risk factors for $\mathrm{ON}$ among nutrition students nationwide.

\section{Materials And Method}

A pilot study with a descriptive cross-sectional design was done on Nutrition and Dietetics students at the Universidad Mayor (UM) campus in Temuco, Chile. The sample was determined by Select Statistical Services with $95 \%$ reliability and 5\% maximum error. Volunteer recruitment was performed institutionally via invitations sent to personal emails, sent out between December 2020 and February 2021. Inclusion criteria were the following: being enrolled in the Nutrition and Dietetics major at UM, showing knowledge about current anthropometric measurements, and being a regular student in a single level of the major. Exclusion criteria included the presence of any current psychiatric treatment and/or diagnosis, and course load irregularities (among different levels).

Volunteers who agreed to participate in the study signed informed consent online, in order to respond anonymously over the same medium. The data collection instrument asked about the following variables: number of years studied, age, gender, weight, height, secondary school, weekly physical activity frequency, number of cohabitating people and Instagram use. Body mass index was also calculated according to the Quetelet equation to classify nutritional status according to World Health Organization directives (13). Instagram use was also calculated, derived from data provided by the app settings (14), measured in minutes and then classified in three categories ( $<1$ hour, 1-3 hours, and $>3$ hours). Subsequently, volunteers answered the ORTO11-ES instrument, whose objective is to measure ON risk based on 11 self-applied items with a minimum score of 1 and a maximum score of 4 . The results achieved were classified as a function of the numerical value of the sum of answers given by study subjects, with a value of 25 or more rated as a negative ON risk, while a value below 25 points characterized the subject as at risk for suffering ON (15).

All data were gathered, organized and processed in Microsoft Excel, and then exported to GraphPad Prism 8.0® software for statistical analysis. Distributions, medians and standard deviations were calculated for general background data. Odds ratio and confidence intervals were calculated for discrete quantitative variables and the 
determination of their $\mathrm{ON}$ risk association. For continuous quantitative variables, the confidence interval, Pearson's $r$ and significance levels were calculated against the ORTO-11-ES score.

We must mention that this work was done following the guidelines of the Helsinki Declaration and approved by the Ethics Committee at the Universidad Mayor campus in Temuco, Chile.

\section{Results}

90 volunteers who agreed to participate in the study were obtained, amounting to $75 \%$ of the total student population in the Nutrition and Dietetics major at Universidad Mayor. This included subjects of both sexes, where $12.2 \%$ were men and the other $87.8 \%$ were women. Regarding participants' characterization (Table 2), a similar distribution was obtained for each level, apart from the first year, where only $7(7.8 \%)$ subjects took part, in contrast with the other levels (20-25\%). Regarding students' secondary schooling, only $7.8 \%$ of respondents came from public state schools, with the majority of people enrolled in this major coming from charter schools (over $70 \%$ ). A similar situation emerges in cohabitation, where over $80 \%$ of study subjects live together with at least two people. By contrast, participation in extracurricular activities shows a similar distribution between those who do take part and those who say they do not. For nutritional status, physical activity and Instagram use background, the main responses were normal weight $(72.2 \%)$, light activity $(43.3 \%)$ and $1-3$ hours of use (63.3\%), respectively. Finally, in regards to the main variable measured, 21 out of 90 subjects presented orthorexia nervosa risk, which amounted to $23.3 \%$ of the sample.

Regarding the continuous quantitative variables measured (Table 3 ), both genders presented an average age of $22.2 \pm 2.6$ years, Body Mass Index (BMI) of $23.2 \pm 3 \mathrm{~kg} / \mathrm{mt}^{2}$, ORTO-11-ES score of $26.8 \pm 3.8$ and an average daily amount of time on Instagram of $135.5 \pm 95.4$ minutes, with a variation coefficient of $70.38 \%$. No statistically significant differences were found regarding differences in these variables by gender among respondents (Table 4).

For the categorized variables and their association with $\mathrm{ON}$ risk, their $\mathrm{OR}$ and respective confidence intervals were calculated, all as described in Table 5. For the cases of gender, extracurricular activities and nutritional status, no association was found with ON risk or its counterpart. For schooling level, being in the second year of the major showed a probability of ON risk 2.22 times higher than other years, followed by third and fifth year students, but with lower figures. For the socioeconomic level provided by reported secondary education establishment, charter schools were categorically associated with ON risk $(\mathrm{OR} 3,00)$ above private schools (OR 0,55 ). Similarly, cohabitation limited to one person or less (OR 2.47) was a factor by comparison with homes shared with 2, 3 or more people. Other evaluated variables presented a dual nature, since limits on declared physical activity are associated with a risk of suffering ON (Sedentary OR 2.42, Heavy OR 3.53), over light and moderate activity (OR 0.44 and 0.55 respectively). This is also reflected in time spent on Instagram, where lower reported time (OR 2.77) and overuse (OR 1.80), are more associated with ON risk than intermediate use levels (entre 1 a 3 horas).

Finally, regarding the correlations determined for continuous quantitative variables (Fig. 1), a positive correlation was reported $(r=0,49)$, which was statistically significant $(p=0.022)$ between the ORTO-11-ES score of people with $\mathrm{ON}$ risk and daily minutes spent on Instagram. A negative correlation was detected for the BMI variable 
among women $(r=-0.27$ and $p=0.014)$ and in the general sample $(r=-0,23$ and $p=0.029)$. In men, age correlated positively with ORTHO-11-ES score, but was not statistically significant (Table 6).

\section{Discussion}

Being a nutrition student is an important risk factor for developing orthorexia nervosa according to different international studies $(9,16-19)$. Considering the rise in enrollment rates and increase in the number of students in Chile, it is necessary to develop incentives which allow for identifying associated factors which promote the condition and allow us to establish lines of action for prevention and management. In this line, the present study constitutes an important precedent as the first work of this nature at the national level, and along with two studies done in Brazil in previous years, the only work undertaken in South America.

The principal results include the evidence of an $\mathrm{ON}$ risk prevalence rate of $23.3 \%$, greater than described for the general population or the rate described by Escobar et al., (2019) among Peruvian medical students (15). Other rates were reported at between 30-80\% among nutrition students, however, all studies used different versions of the ORTHO instrument, making comparisons unviable. A publication by Dunn et al. declared that these values were overestimated, apart from indistinct use of the terminology related with diagnosis and risk, demonstrating the need for greater caution when comparing these results. It would be interesting to analyze which out of all the ORTHO versions generated has a better diagnostic capacity, especially because of the ORTHO-15 results which report rates above $50 \%$ of evaluated samples. It is also important to mention that these evaluations mainly focused on European populations, where sociodemographic and sanitary realities are very different from the reality of Chilean university students (20-22).

One major goal of the present study was to identify factors associated to ON risk in nutrition students. Curiously, being in the second year is more associated with ON risk than other levels. Even as the major progresses, and nutritional knowledge therefore expands, the risk diminishes. The present result could be mediated by the courses done during the second year of the major, which involves a sudden inclusion of disciplinary courses associated with self-measurement of body segments, including Nutritional Status Evaluation, along with quantitative food evaluation in areas including Basic Nutrition and Food Planning $(23,24)$. The drop in ON prevalence by level as the years advance (Table 5) could be due to the orientation of the following courses, which focus more on the qualitative value of food and healthy criteria about body composition, contributing a non-reductionist training regarding the characterization of food and ideal body composition. It would be interesting to compare this with other studies; however, there is no risk characterization by level in the studies done to date, making our results unprecedented in this sense.

Regarding the other associated factors, in prior studies secondary educational establishment type was identified as a variable associated with ON risk. During 2015, Jerez et al. (7), evaluated a cohort of secondary school students who came from different schools, reporting higher rates in public state schools. This reoccurred in our study, where students from private schools had only a $15 \%$ risk of ON, which was lower than charter school students at 28\% (OR 3.00). Considering this, along with Chilean inequality levels, it would be interesting to evaluate in future studies whether food and nutrition education is a protective factor against ON in adolescence and/or adulthood, as has been reported with other educational interventions against Anorexia and Bulimia (25, 26). It could also be possible that, depending on socioeconomic level, home diet quality will show concrete 
differences with knowledge acquired in higher education, placing individuals in undesired vulnerable conditions which are hard to remedy (27).

Another factor associated with ON risk observed in this sample is limited cohabitation with one person or less, which places perceived social support as a variable to consider, as reported by various publications discussing eating disorders more generally (28). However, when queried about extracurricular activities, a lack of engagement with them did not constitute a risk factor associated with $\mathrm{ON}$. This could be influenced by the variability of activities performed, with an understanding that not all are associated with increasing social support, including practicing individual sports and exercise (29). Simultaneously, the current strict social distancing measures in Chile could be a limiting factor for positive aspects of extracurricular activities considering how in-person activities have transformed into remote events (30). Furthermore, nutritional status in this student sample was not an element for consideration, which could be related to specific social pressure in this population group, with their general preoccupation for body composition and nutritional status, regardless of what their classification may be.

The results for the physical activity and Instagram use variables are interesting, since limiting categories throw out association with ON risk. This situation presents the fact that both sedentary status and heavy physical activity are factors on which to focus. The same thing happens with social network use, where spending less than 1 hour per day and spending 3 or more hours per day were both factors associated with ON risk in this sample. This provides evidence for avoidance as a coping strategy for this problem among sedentary subjects who present limited interaction with social media; the latter point is unprecedented in comparison with international evidence (14). On the other extreme, subjects who undertook excessive physical activity and overused Instagram could be influence by beauty standards created in gyms and social networks, including “Fitspiration" dynamics (31).

It should be mentioned that there are important limitations on this study considering the number of subjects evaluated. However, the sample is a representative number for the quantity of people enrolled in an average university Nutrition and Dietetics major in Chile. This is why the present pilot initiative presents several interesting variables worth investigating which had not been identified in other studies, such as major year and duality in social media use. However, considering the nature of the study, interpretation should be taken with caution considering the design used.

Future studies should try to have more representativeness, expanding the sample size and considering schools from different regions around the country in order to reproduce the geographical and populational heterogeneity of Chile. Furthermore, a longitudinal design contrasted with a control population would allow us to evaluate the risk or protective factor condition of the variables which were studied, vis-à-vis ON risk in this specific population.

\section{Conclusion}

There is a worrying rate of orthorexia nervosa risk in the pilot sample studied here, showing that physical activity, study years, cohabitation, secondary school type and Instagram use are risk factors for the condition. This study needs to be replicated in samples which better represent Chilean national diversity, and longitudinal studies need to be done with control groups which can confirm these elements as risk factors for Orthorexia Nervosa, which may in the future be able to establish guidelines for prevention strategies. 


\section{Declarations}

Ethics approval: This study was approved by the Scientific Ethics Committee at Universidad Mayor, Temuco, accredited by Resolution \# J1-6888 - Regional Health Secretariat - Araucanía Region.

Data and material availability: The data sets used and analyzed during this study are available from the corresponding author upon personal request.

Conflicts of interest: The authors declare no conflicts of interest.

Funding: This study was economically supported by the Research Vice-rectory at Universidad Mayor, Temuco.

Author contributions: MV, NO, SM and NA designed the study, and gathered and processed data. PV reviewed composition and contributed to the discussion related to the psychological aspects. ML analyzed the data, composed the publication and supervised the entire research process.

Acknowledgments: We thank the university science faculty authorities for facilitating the development of this study.

\section{References}

1. Kalra S, Kapoor N, Jacob J. Orthorexia nervosa. J Pak Med Assoc. 2020;70(7):1282-4.

2. Koven NS, Wabry A. The clinical basis of orthorexia nervosa: Emerging perspectives. Neuropsychiatr Dis Treat. 2015;11:385-94.

3. Gibson D, Workman C, Mehler PS. Medical Complications of Anorexia Nervosa and Bulimia Nervosa. Psychiatr Clin North Am [Internet]. 2019;42(2):263-74. Available from: https://doi.org/10.1016/j.psc.2019.01.009.

4. Kaźmierczak-Wojtaś N, Patryn R, Zagaja A, Drozd M, Niedzielski A. Prevalence and characteristics of orthorectic disorders in adolescence and young people: Polish preliminary studies. Nutrients. 2021;13(5).

5. Dunn TM, Gibbs J, Whitney N, Starosta A. Prevalence of orthorexia nervosa is less than $1 \%$ : data from a US sample. Eat Weight Disord. 2017;22(1):185-92.

6. McComb SE, Mills JS. Orthorexia nervosa: A review of psychosocial risk factors. Appetite [Internet]. 2019;140(May):50-75. Available from: https://doi.org/10.1016/j.appet.2019.05.005.

7. Jerez FT, Lagos HR, Valdés-Badilla P, Pacheco PE, Pérez CC. Prevalence of orthorexic behaviour in high school students of Temuco. Rev Chil Nutr. 2015;42(1):41-4.

8. Moroze RM, Dunn TM, Craig Holland J, Yager J, Weintraub P. Microthinking About Micronutrients: A Case of Transition From Obsessions About Healthy Eating to Near-Fatal "Orthorexia Nervosa" and Proposed Diagnostic Criteria. Psychosomatics [Internet]. 2015;56(4):397-403. Available from: http://dx.doi.org/10.1016/j.psym.2014.03.003.

9. Abdullah MA, Al Hourani HM, Alkhatib B. Prevalence of orthorexia nervosa among nutrition students and nutritionists: Pilot study. Clin Nutr ESPEN [Internet]. 2020;40(xxxx):144-8. Available from: https://doi.org/10.1016/j.clnesp.2020.09.175. 
10. Malmborg J, Bremander A, Olsson MC, Bergman S. Health status, physical activity, and orthorexia nervosa: A comparison between exercise science students and business students. Appetite [Internet]. 2017;109:13743. Available from: http://dx.doi.org/10.1016/j.appet.2016.11.028.

11. Ministerio de Salud (MINSAL). Oferta de profesionales de salud en Chile. Evolución 2007-2015 de la matrícula y los titulados en las universidades nacionales. 2016;1-32.

12. Crovetto M, Lopez D. What happening with nutritionist training in Chile? Rev Chil Nutr. 2020;47(4):677-84.

13. Nuttall FQ. Body mass index: Obesity, BMI, and health: A critical review. Vol. 50: Nutrition Today. Lippincott Williams and Wilkins; 2015. pp. 117-28.

14. Turner PG, Lefevre CE. Instagram use is linked to increased symptoms of orthorexia nervosa. Eat Weight Disord. 2017;22(2):277-84.

15. Escobar L, Roberth C, Mayhuasca H. Riesgo De Ortorexia Nerviosa En Estudiantes De Medicina De Una Universidad Privada Peruana [Internet]. Universidad Peruana Cayetano Heredia. 2019. Available from: https://www.mendeley.com/catalogue/ee265cbc-2676-3e81-a7c6-51606cae6cf5/? utm_source=desktop\&utm_medium=1.19.4\&utm_campaign=open_catalog\&userDocumentld=\%7B29784fdc4fa0-4d61-b6e7-fc2422f2186d\%7D\%0Ahttp://repositorio.upch.edu.pe/handle/upch/6401.

16. Karakuş B. Orthorexia Nervosa Trends Among Students Of Nutrition And Dietetics Department At A University In Istanbul. North Clin Istanbul. 2017;4(2):117-23.

17. de Souza QJOV, Rodrigues AM. Comportamento de risco para ortorexia nervosa em estudantes de nutrição. J Bras Psiquiatr. 2014;63(3):201-4.

18. Penaforte FRO, Barroso SM, Araujo ME, Japur CC. Orthorexia nervosa in nutrition students: Association with nutritional status, body satisfaction and coursed period. J Bras Psiquiatr. 2018;67(1):18-24.

19. Grammatikopoulou MG, Gkiouras K, Markaki A, Theodoridis X, Tsakiri V, Mavridis P, et al. Food addiction, orthorexia, and food-related stress among dietetics students. Eat Weight Disord [Internet]. 2018;23(4):45967. Available from: http://dx.doi.org/10.1007/s40519-018-0514-1.

20. Ferrer L, Cianelli R, Guzman E, Cabieses B, Irarrázabal L, Bernales M, et al. Chilean University Students: Knowledge and Concern About HIV/AIDS. J Assoc Nurses AIDS Care. 2007;18(5):51-6.

21. Celis-Morales C, Salas C, Alduhishy A, Sanzana R, Martínez MA, Leiva A, et al. Socio-demographic patterns of physical activity and sedentary behaviour in Chile: Results from the National Health Survey 2009-2010. J Public Heal (United Kingdom). 2016;38(2):e98-105.

22. Barranco-Ruiz Y, León CC, Villa-González E, Leal XP, Chillón P, Rodríguez-Rodríguez F. Active commuting to university and its association with sociodemographic factors and physical activity levels in chilean students. Med. 2019;55(5).

23. Universidad Mayor Temuco U. Malla curricular: Nutrición y Dietética. 2021.

24. Pontificia Universidad Catolica de Chile U. Malla Curricular Nutrición y Dietética. 2021.

25. Silverstein LS, Haggerty C, Sams L, Phillips C, Roberts MW. Impact of an oral health education intervention among a group of patients with eating disorders (anorexia nervosa and bulimia nervosa). J Eat Disord. 2019;7(1):1-6.

26. Gumz A, Weigel A, Daubmann A, Wegscheider K, Romer G, Löwe B. Efficacy of a prevention program for eating disorders in schools: a cluster-randomized controlled trial. BMC Psychiatry. 2017;17(1):293. 
27. Leyton D, Vásquez A, Fuenzalida V. The experience of students in vulnerablecontexts in different University Higher Education Institutions (IESU, by the Spanish acronym): Research outcomes. Calid en la Educ. 2012; (37):61.

28. Jenkins PE, Rienecke RD, Conley CS, Meyer C, Blissett JM. The relation between eating disorder symptoms and impairment. J Nerv Ment Dis. 2015;203(6):452-8.

29. Singh A, Singh A. Comparative Study of Social Support among Individual, Team and Dual Sports Athletes. Int J Curr Res Rev. 2017;9(14):19-22.

30. Grebe G, Velez JA, Tiutiunnyk A, Aragón-Caqueo D, Fernández-Salinas J, Navarrete M, et al. Dynamic Quarantine: A comparative analysis of the Chilean Public Health response to COVID-19. Epidemiol Infect. 2020.

31. Carrotte ER, Prichard I, Lim MSC. "fitspiration" on social media: A content analysis of gendered images. J Med Internet Res. 2017;19(3):1-9.

\section{Tables}

Due to technical limitations, the tables are only available as a download in the supplementary files section.

\section{Figures}



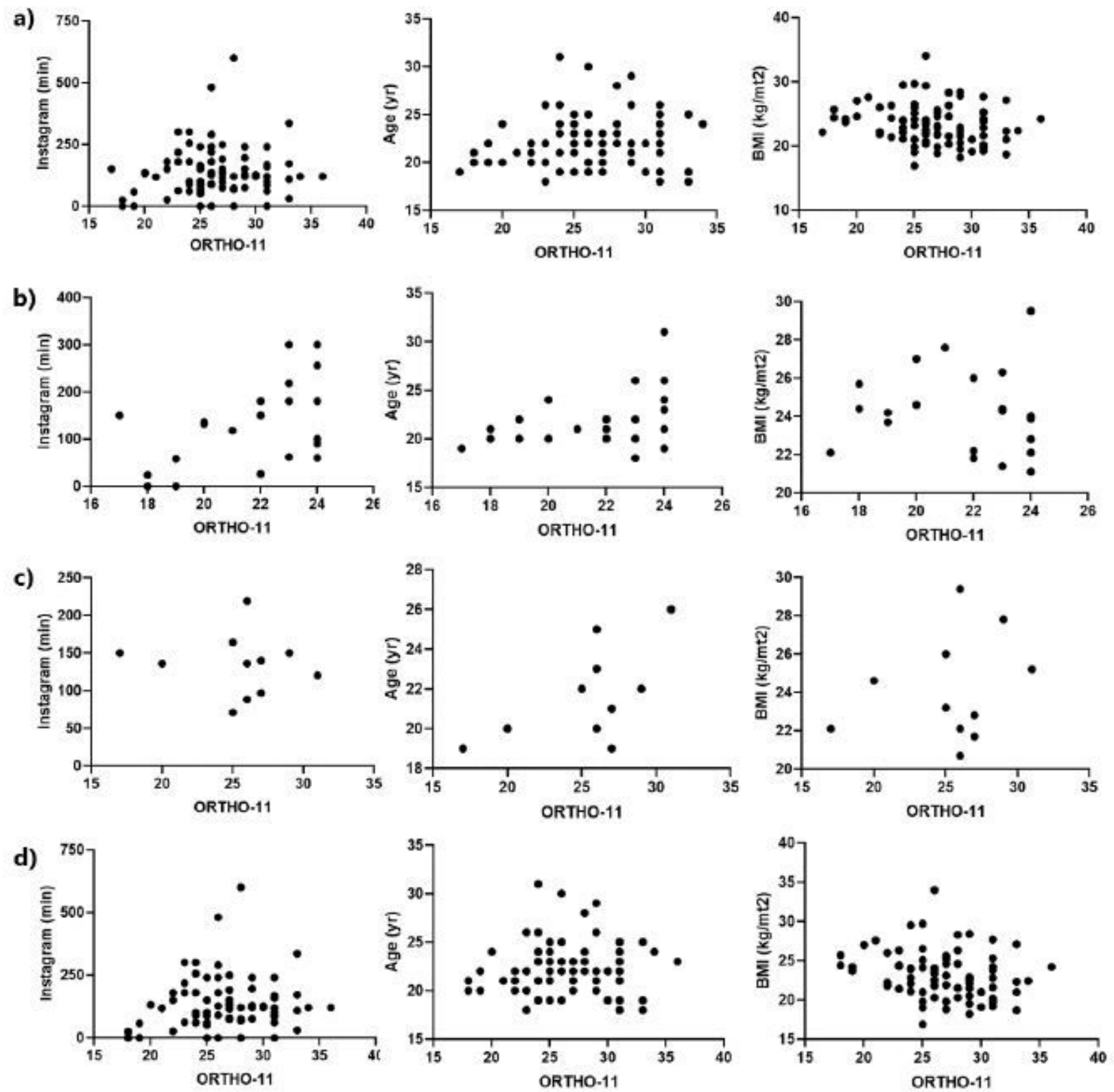

(a) All samples, (b) Subjects with Orthorexia Nervosa risk, (c)Men, (d) Women.

Figure 1

Correlation between ORTHO-11 results, Age, BMI and Instagram use

\section{Supplementary Files}

This is a list of supplementary files associated with this preprint. Click to download.

- Tables.pdf 